\title{
POLIFONIA: ORIGEM E EVOLUÇÃO DO CONCEITO EM OSWALD DUCROT
}

\author{
Leci Borges Barbisan \\ Marlene Teixeira
}

RESUMO: Quelques textes, publiés entre 1980 et 2001, traitant de la notion de Polyphonie dans la Théorie de l'Argumentation dans la Langue, conçue par Oswald Ducrot et des collaborateurs, sont présentés dans ce travail. On y cherche à montrer comment l'auteur s'est inspiré dans la théorie de Charles Bally pour créer la notion de polyphonie et comment, tout au long de vingt ans, il est passé de la pragmatique à la notion d'énonciateur comme source de points de vue que le locuteur met en scène dans son discours.

PALAVRAS-CHAVE: Polifonia, Teoria da Argumentação na Língua, locutor, enunciador, pontos de vista.

\section{INTRODUÇAO}

A noção de polifonia em Ducrot aparece pela primeira vez no capítulo 1 de Les mots du discours (1980), é retomada, com modificações, em Le dire et le dit (1984) e retrabalhada nas conferências de Cali (1988). Depois disso, só recentemente o autor volta ao tema, em artigo publicado

Leci Borges Barbisan é professora da PUCRS.

Marlene Teixeira é professora da UNISINOS. 
pela revista escandinava Polyphonie - linguistique et littéraire (2001) com o título Quelques raisons de distinguer "locuteurs" et "énonciateurs", escrito para responder à exclusão da noção de enunciador proposta pelo grupo escandinavo dedicado ao estudo da polifonia (ScaPoLine).

A palavra polifonia, originalmente, refere uma classe de composição musical, caracterizada pela sobreposição de muitas vozes ou muitos instrumentos, exprimindo cada qual suas idéias, quase sempre em ritmos diferentes (BORBA, 1963, p. 392). Ducrot utiliza essa palavra numa extensão (que ele diz ser bastante livre) à lingüística do uso que dela faz Bakhtin $^{1}$ na literatura. Bakhtin aborda a polifonia dentro do universo enunciativo de um texto. Ducrot opera o conceito num nível lingüístico, indicando, através dele, a possibilidade de um desdobramento enunciativo dentro do próprio enunciado, à maneira de uma encenação teatral em que atuam diferentes personagens.

Ao longo de seu desenvolvimento, a teoria polifônica tem passado por modificações, provocadas, muitas vezes, pelas críticas que recebe, com as quais Ducrot dialoga constantemente, atento aos problemas apontados, buscando novos argumentos para sustentar suas posições ou, se for o caso, reformulando-as. A própria natureza do método de Ducrot, segundo o qual a análise de um fato à luz de uma determinada teoria levanta uma camada, mas debaixo fica outra e assim de maneira infinita, institui uma atitude de vigilância em relação à teoria que não favorece sua cristalização. Na visão do autor, o problema principal para o teórico é mostrar que a camada levantada na segunda análise é mais profunda que a anterior, de modo que a segunda explicação sirva para elucidar dados não recobertos pela primeira, sem que se chegue nunca a uma explicação definitiva.

As nuances de cada camada levantada são freqüentemente muito sutis. Em razão disso, julgamos procedente retomar os principais textos em que Ducrot aborda a polifonia numa tentativa de surpreender seus movimentos mais significativos. Nosso objetivo é sobretudo didático: tentar um mapeamento da trajetória desse conceito, com já mais de 20 anos, que possa servir de referência aos que se iniciam no tema.

Acrescentamos ainda um motivo para revisitar a concepção polifônica da enunciação: a grande contribuição que ela tem trazido à descrição semântica dos enunciados, permitindo dar conta das mais finas combinações enunciativas (NEGRONI \& TORDESILLAS, 2000, p. 15).

Segundo Ducrot (1989), foi a teoria da enunciação de Charles Bally (1965) que lhe permitiu "observar" o diálogo que ocorre no interior

${ }^{1}$ Bakhtin trata da polifonia em Problemas da poética de Dostoiévski. Rio de Janeiro: Forense-Universitária, 1981.

162 
do enunciado como encenação de diferentes vozes, aquelas dos "enunciadores". Iniciamos por uma retomada desse texto de reconhecimento a Bally no intuito de situar as origens das reflexões ducrotianas sobre a polifonia.

\section{BALLY, O INSPIRADOR}

Em obra intitulada Logique, strucuture, énonciation (1989), no capítulo VII, Ducrot se propõe a explicar como, a partir da leitura de Linguistique générale et linguistique française de Charles Bally (1965), ele encontrou inspiração para sua teoria lingüística da polifonia. Parte da afirmação de Bally de que a língua é um instrumento que permite a comunicação de um pensamento pela palavra. Essa idéia já estaria na Gramática de Port-Royal, segundo a qual, a língua serve para significar nossos pensamentos. Comparando as duas posições, Ducrot observa que Bally fala de comunicar um pensamento, enquanto Port-Royal fala de significar nossos pensamentos. Então - e é dessa observação que o autor parte para conceber sua teoria da polifonia - segundo Bally, há a possibilidade de que o pensamento comunicado não seja o do sujeito falante.

Outro aspecto observado por Ducrot é que Bally contrapõe pensamento a idéias, noções que têm implicações para a descrição semântica. Segundo o autor, todo pensamento consiste em reagir a uma representação, reação que pode ser de tipo intelectual, afetivo ou volitivo. Assim, prossegue Ducrot, o pensamento se decompõe em um elemento ativo ou subjetivo (a reação) e um elemento passivo ou objetivo (a representação). Trata-se da mesma concepção encontrada em Descartes, segundo a qual o pensamento se analisa como uma decisão de vontade (elemento subjetivo), a propósito de idéias objetivas, concebidas pela compreensão.

É uma repartição da significação semelhante que fazem os filósofos da linguagem modernos quando falam de força ilocutória de uma proposição. Há em comum, entre essa teoria moderna e a representação tradicional do pensamento, a dissociação entre um elemento subjetivo (reação de Bally, força ilocutória da pragmática) e um elemento objetivo (representação para Bally, proposição para Searle).

As concepções de Descartes, Port-Royal e Bally e a teoria dos atos de fala apresentam raízes diferentes: as de tipo cartesiano se apóiam sobre uma análise do pensamento, enquanto Searle se ocupa da atividade de comunicação. Além disso, a força ilocutória caracteriza a enunciação de uma frase. Já quando se diz que o pensamento significado por uma frase é uma reação a uma representação, não se diz que a reação comanda a 
enunciação. Essa relação diferente entre a força ilocutória e a reação em relação à enunciação tem conseqüência quanto à identidade do sujeito. Assim, o sujeito do ato ilocutório é o sujeito falante; na concepção de Bally, não se percebe uma identidade entre o sujeito da reação comunicada e o sujeito falante. Ao contrário, a dissociação entre esses dois sujeitos é fundamental para Bally. Ducrot se posiciona em relação a esses fatos dizendo que o sentido concerne à enunciação, como afirma a teoria dos atos de fala, mas ele admite também que o sentido pode mostrar outros sujeitos, diferentes do sujeito falante.

Tendo esclarecido que, para Bally, uma frase é um pensamento e que um pensamento é uma reação a uma representação, Ducrot afirma que as noções de modus e de dictum, retomadas por Bally, da filosofia medieval, se definem sem dificuldade. Sob a forma de $X$ tem tal reação diante de tal representação, $\mathrm{X}$ tem tal reação é o modus em que X é sujeito modal. $\mathrm{O}$ tipo de reação é o verbo modal. O dictum é a representação objeto da reação. Se a estrutura semântica de uma frase é sempre do tipo modus+dictum, a configuração significante realiza explicitamente essa estrutura, representando o modus e o dictum e, no interior do segmento modal, o sujeito modal e o verbo modal. Mas às vezes, o sujeito modal ou o verbo modal, ou ambos, não são representados na frase, são deixados implícitos, como em É preciso que você pare de fumar em que o sujeito modal pode ser atribuído ao locutor ou a uma autoridade que o locutor representa. Assim, por trás da superfície, ou do explícito, pode aparecer um modus e uma divergência entre o sujeito falante e o sujeito modal, ou seja, uma distinção entre pensamento comunicado e pensamento pessoal de quem fala.

Mas esses sujeitos também podem coincidir quando o sujeito falante atribui a si mesmo um pensamento que no entanto não é o seu, como no caso da mentira ou da ironia. O sujeito falante torna-se, então, o desdobramento de dois pensamentos diferentes: o seu e aquele que ele comunica como sendo o seu e que na verdade não o é. O que parece importante na dissociação dos dois sujeitos não é marginal ou acidental. A dissociação está relacionada à própria natureza do signo que implica que o sujeito falante não comunica seu próprio pensamento, mas um pensamento que pode ser ou não conforme ao seu.

Bally apresenta três casos de relações entre pensamento pessoal inerente a toda comunicação:

- 1a) o pensamento comunicado é atribuído ao sujeito falante e corresponde efetivamente ao pensamento desse sujeito;

- 1b) o pensamento comunicado é atribuído ao sujeito falante, 
mas não corresponde ao do sujeito falante: fala desonesta ou não-séria;

- $\quad$ 2) O pensamento comunicado não é atribuído ao sujeito falante, logo, o sujeito falante é diferente do sujeito modal.

Ducrot subdivide o segundo caso. Tanto em (2a) como em (2b), o sujeito falante seria diferente do sujeito modal. Mas em (2a) o pensamento comunicado seria conforme ao pensamento da pessoa a quem ele é atribuído; em (2b) aconteceria o contrário, em que se faria dizer por alguém, que nunca o disse, alguma coisa que não se ousa dizer.

$\mathrm{O}$ autor desenvolve a idéia de Bally de que a modalidade é incorporada no dictum sob a forma de um adjetivo de julgamento e de apreciação. É o caso de Esta fruta é deliciosa em que, segundo Bally, há a estrutura semântica Tenho prazer em comê-la, o sujeito modal eu, o verbo modal ter prazer e o dictum eu como esta fruta. O adjetivo deliciosa é um significante, faz parte do dictum, então o dictum designa uma entidade da ordem do significante. Mas não se trata da representação à qual o sujeito modal reage, já que esta pertence ao significado. $\mathrm{O}$ adjetivo deliciosa exprime não uma representação, mas uma reação. A explicação melhor, segundo Ducrot, é considerar o dictum como uma representação da realidade. Pode-se dizer que o predicado gramatical de Esta fruta é deliciosa reúne um modus (tenho prazer) e um dictum (comer).

Ducrot diria que o locutor - pessoa à qual se atribui a responsabilidade pela enunciação - põe em cena dois enunciadores que, a respeito do mesmo objeto, reagem de modo oposto. Essa seria uma solução polifônica. Para se admitir uma solução polifônica desse tipo, é preciso aceitar a coexistência possível de vários modus e vários dictum no sentido de um enunciado único. Nada proíbe que se veja na proposta de Bally, para um mesmo enunciado, sujeitos modais distintos: o enunciado, diz Ducrot, poderia então representar os pontos de vista ou as reações de diferentes pessoas. O que sugere uma concepção teatral da enunciação: o sentido do enunciado descreve a enunciação como a confrontação de pontos de vista diferentes, que se justapõem, se superpõem ou se respondem (1989, p. 178). Análises feitas ao modo de Bally, explica Ducrot, obrigariam a reconhecer não apenas diversos modus, mas também diversos sujeitos modais.

Não se pode dizer que a leitura de Bally leve a uma concepção teatral - a enunciação vista como a encenação de diferentes atitudes. Nada, porém, na teoria de Bally, se opõe a essa concepção que é mesmo inevitável quando se analisam exemplos complexos com o apoio dessa teoria, conforme Ducrot.

Aos papéis de sujeito falante e de sujeito modal deve-se acres- 
centar um terceiro papel: o de sujeito comunicante, diverso do sujeito modal, distinguindo o sujeito de fazer saber do sujeito de estar convencido. Já a diferenciação entre sujeito comunicante e sujeito falante é menos imediata porque o sujeito falante é exterior, por definição, ao sentido, não aparecendo na forma canônica do sentido. Mas Bally apresenta exemplos em que duas pessoas diferentes são sujeito falante e sujeito comunicante.

Embora Bally não tenha ido longe nessa direção, diz Ducrot, foi ele quem a apontou. Seu trabalho apresenta-se então como decisivo para as reflexões ducrotianas que sintetizamos a seguir.

\section{POLIFONIA: PRIMEIRAS TEORIZACCÕES}

No capítulo 1 de Les mots du discours (1980, p. 43), Ducrot faz a primeira alusão ao conceito de polifonia, que ele formula junto à tese de que o enunciado veicula uma imagem de sua enunciação. A idéia central desenvolvida pelo autor é que, nessa descrição da enunciação que constitui o sentido do enunciado, se deve distinguir o autor das palavras (locutor) e os agentes dos atos ilocutórios (enunciadores). Ao par locutor/ enunciador, Ducrot associa o par alocutário/destinatário. O alocutário é aquele a quem a enunciação do locutor se dirige e o destinatário é aquele a quem os atos ilocutórios produzidos pelo enunciador efetivamente se destinam.

Nesse momento, Ducrot assinala que é preciso distinguir a noção de polifonia da possibilidade bem conhecida de relatar num discurso o discurso de um outro (quer seja em estilo direto como indireto). Não basta, para que se possa falar de polifonia, que se trate, no discurso atribuído a um locutor L, de um discurso de uma outra pessoa L', porque a presença da fala de L' na de L pode estar ligada ao simples discurso relatado e isso exclui, segundo o autor, a polifonia (Ibid, p. 44).

Em Les mots du discours, não é feita a distinção entre o locutor e o sujeito empírico, aspecto que vai receber atenção especial nos demais textos sobre o tema. Além disso, os enunciadores são descritos no quadro conceptual da teoria dos atos de fala, como agentes de atos ilocutórios distintos. De fato, em sua teorização anterior a 1984 Ducrot mantém um diálogo constante com a pragmática anglo-saxã, com ênfase especial na discussão do estatuto dos atos ilocutórios. Esse quadro se altera em Le dire et le dit (1984) e, principalmente, a partir da teoria dos topoi argumentativos (1989), que ele formula juntamente com Anscombre para, dentro do quadro estruturalista saussuriano, desenvolver a tese da argumentação inscrita na língua (FLORES, 2001, p. 41). 
Em 1984², Ducrot efetivamente elabora sua teoria da polifonia, desenvolvendo indicações feitas no primeiro capítulo de Les mots du discours e corrigindo-as em alguns aspectos. Nesse segundo momento, a tese de que é necessário distinguir locutor de enunciador é mantida, mas essa distinção apresenta-se sob novas bases.

a) O locutor é apresentado como alguém a quem se deve imputar a responsabilidade pelo enunciado. É a ele que referem o pronome $e u$ e as demais marcas de primeira pessoa.

b) O locutor, uma ficção discursiva, é diferenciado do autor empírico, elemento da experiência (1987, p. 187). Aqui Ducrot deixa clara sua recusa em introduzir a idéia de um produtor de fala integrando a descrição do sentido do enunciado. Nesse aspecto, sua teoria diferenciase crucialmente de abordagens discursivas ${ }^{3}$, já que não é o processo de produção da enunciação que polariza o interesse, mas o simples acontecimento constituído pelo aparecimento de um enunciado ${ }^{4}$.

c) O locutor recebe duas representações diversas:

- locutor enquanto responsável pela enunciação [L]

- locutor enquanto ser no mundo [Y].

Como subdivisões do locutor, ambas são representações internas ao enunciado e, portanto, seres do discurso, com estatuto metodológico diverso daquele do sujeito falante, figura não-enunciativa e externa ao discurso. [L] é constituído no nível do dizer, através da forma do enunciado, e se representa como responsável pela enunciação; [Y] é constituído no nível do dito, através do conteúdo do enunciado, é o ser empírico do mundo, referido pelo enunciado, ou seja, representa a origem do enunciado (1987, p. 188). A identificação de [Y] só é possível através de [L]. [L] qualifica o que [Y] faz, realizar um ato.

Por exemplo, em Eu desejo, Eu remete a [Y], pois não é enquanto locutor que se experimenta o desejo, mas enquanto ser do mundo, e independentemente da asserção que se faz dele. O "ato de desejar", que

${ }^{2}$ Citaremos as páginas da publicação em português, datada de 1987.

${ }^{3}$ Referimo-nos aqui a perspectivas de análise de discurso desenvolvidas em torno da figura de Michel Pêcheux.

${ }^{4} \mathrm{Em}$ entrevista à revista argentina Punto de Vista (n. 21, agosto de 1984, p. 24), Ducrot explicita sua diferença com a perspectiva aberta por Pêcheux, às quais ele atribui uma concepção de enunciação como fato empírico, atividade realizada por um ser humano que produz um certo enunciado influenciado por determinada restrição ou força interna ou externa. Ele diz não se interessar pelo fato de que todo enunciado leve em si mesmo marcas das condições em que foi produzido. Em sua descrição lingüística não intervém a situação social, empírica dos interlocutores, pois para ele o sentido de um enunciado consiste em indicações sobre o fato de seu aparecimento. Isso não significa negar a interferência dos fatores de ordem social na constituição do sentido, mas apenas demarcar o ponto de vista desde o qual ele escolheu olhar para a linguagem. 
não existe senão na fala em que se realiza, pertence a $[\mathrm{L}]$ : $[\mathrm{L}]$ realiza $\mathrm{o}$ ato de desejar afirmando que $[\mathrm{Y}]$ deseja. A distinção $[\mathrm{L}]$ e $[\mathrm{Y}]$ permite que Ducrot precise sua posição sobre os performativos explícitos. O autor contesta que se possa realizar um ato de linguagem pelo simples fato de se declarar explicitamente realizá-lo. Tomar "Eu desejo" como tendo a propriedade de designar e realizar o ato de "desejar" é confundir linguagem com metalinguagem, ou seja, é entender DESEJAR (conceito teórico) como sinônimo do verbo desejar. É nesse sentido que Ducrot formula a hipótese da delocutividade e diz que é a derivação delocutiva que introduz a concepção jurídica: realizar o ato que se pode realizar, entre outros meios, pela forma convencionalizada Eu desejo. A hipótese da delocutividade diz como o conceito DESEJAR se lexicaliza em Eu desejo. [L] diz 1 (assevera) que [Y] diz 2 (mostra), ou seja, [L] faz saber que [Y] realiza o ato de desejar.

d) A noção de enunciador é reformulada.

Em Les mots du discours (1980), Ducrot define os enunciadores dizendo que eles são sujeitos dos atos ilocutórios elementares (afirmação, pergunta, etc.). Enunciadores são, então, aqueles a quem se atribui a responsabilidade pelos atos ilocutórios que o enunciado do locutor veicula.

Na concepção de 1984, o autor diz que as vozes veiculadas através da enunciação expressam pontos de vista que o locutor organiza para identificar-se com os mesmos ou para se opor a eles. Essas vozes não são explicitadas. Sua existência é decorrente da imagem que delas oferece a enunciação produzida por [L]. Os enunciadores são seres considerados como se expressando através da enunciação, sem que para tanto lhe sejam atribuídas palavras precisas. Diz-se que eles falam, mas somente no sentido em que a enunciação expressa seu ponto de vista, sua posição, mas não, no sentido material do termo, suas palavras. Portanto, eles não podem produzir atos ilocutórios.

e) Além da polifonia no nível dos enunciadores, é descrita uma polifonia no nível do locutor.

Na versão de 1984, Ducrot trata os casos de dupla enunciação, onde inclui o RED (relato em estilo direto), como uma primeira forma de polifonia (1987, p. 191). Pode-se dizer, então, que, para o autor, há duas formas de polifonia: uma que ocorre no nível do locutor e uma - bem mais freqüente - que ocorre no nível dos enunciadores. Ducrot desenvolve a segunda forma de polifonia.

Para melhor elucidar a distinção dos três sujeitos - autor/locutor/ enunciador -, Ducrot busca referência em Genette, dizendo que tal distinção se aproxima da análise da narrativa proposta por esse autor em Figures 
III. O escritor de Genette, o indivíduo que inventa a história, não pertence à própria narrativa, do mesmo modo que o sujeito falante de Bally não entra no sentido do enunciado. O narrador de Genette, a voz que conta os acontecimentos, é semelhante ao sujeito comunicante, o ser que faz saber. A analogia é grande entre sujeito modal ou pensante e o centro de perspectiva de Genette, ou seja, aquele que vê, aquele cujo ponto de vista é apresentado nos acontecimentos. É por essa analogia que a teoria polifônica é conhecida também como uma concepção "teatral" dos atos de linguagem (1987, p. 216).

A teoria polifônica da enunciação provoca mudanças na teoria da pressuposição e na teoria da argumentação de Ducrot. A pressuposição passa a ser descrita como apresentando dois enunciadores, E1 e E2, responsáveis, respectivamente, pelos conteúdos pressuposto e posto. E2 é identificado ao locutor, enquanto E1 é identificado a $O N$, uma voz coletiva no interior da qual o locutor está localizado (1987, p. 216-7).

A relação da polifonia com a teoria da argumentação na língua está focalizada nas conferências de Cali (1988) referidas a seguir.

\section{POLIFONIA EARGUMENTAÇAO}

O livro que apresenta a série de conferências que Ducrot pronunciou em Cali, na Colômbia (1988), inicia pela referência ao termo polifonia empregado por Bakhtin para caracterizar uma forma de literatura, qualificada como polifônica ou carnavalesca, em que vários personagens se apresentam por si mesmos, e não são julgados pelo autor, como se vê na obra de Dostoiewski. Essa forma de literatura opõe-se à dogmática, de que as novelas de Tolstoi são o exemplo, na qual se expressa uma única voz, a do autor, que julga os personagens. A proposta de Ducrot é de levar a idéia de polifonia para o enunciado, definido por ele como segmento de discurso.

Nos textos de 1988 mantém-se a idéia de que o sujeito falante remete a várias funções: a de sujeito empírico, a de locutor e a de enunciador. O sujeito empírico escapa ao interesse do lingüista que deve descrever o que está no enunciado, o que diz o enunciado e não as condições externas de produção. O locutor é o responsável pelo enunciado e é nele marcado. Os enunciadores são os diferentes pontos de vista, são pontos de perspectiva abstratos. Assim, o enunciado apresenta um diálogo cristalizado.

É nesse momento que Ducrot faz intervir o conceito de polifonia em sua Teoria da Argumentação na Língua, integrando-o ao estudo da argumentação, incluindo-se aí também a noção de topos. Para que se possa compreender de que modo Ducrot formula o conceito de polifonia nessa 
obra, faz-se necessária a definição do conceito de topos. A exposição que será feita neste item procura, primeiramente, mostrar como a polifonia é vinculada à noção de argumentação; a seguir, focaliza a relação entre polifonia e topos.

Embora nos textos de Cali a noção de polifonia não se distinga sensivelmente daquela que se lê em trabalhos anteriores, Ducrot apresenta aí um desenvolvimento que não se encontra em outros lugares. Um dos aspectos desse desenvolvimento é a definição dos elementos constitutivos do sentido na descrição polifônica: o primeiro deles é a apresentação dos pontos de vista dos diferentes enunciadores presentes no enunciado. $\mathrm{O}$ segundo é a indicação da posição do locutor em relação a esses enunciadores. Há três posições possíveis: aquela em que o locutor se identifica com um dos enunciadores, como é o caso da asserção; aquela em que ele o aprova, como no exemplo da pressuposição; finalmente aquela em que há oposição entre locutor e enunciador, como acontece no humor. Um terceiro elemento constitutivo do sentido é o da identificação de um enunciador com uma pessoa, como se vê na ironia.

Nessa mesma conferência, Ducrot explicita sua posição em relação aos atos de fala da pragmática. Enquanto na teoria dos atos de fala o sentido é constituído por dois elementos: uma força ilocutória e um conteúdo proposicional - o que mostra que o locutor toma uma única atitude no enunciado, atitude indicada pela força ilocutória - na teoria da polifonia, o enunciado apresenta diferentes pontos de vista e o locutor toma atitudes em relação a esses pontos de vista.

Essa concepção de polifonia é aplicada a seguir a exemplos argumentativos, integrando a polifonia à argumentação. $\mathrm{O}$ exemplo estudado contém o conector mas em enunciado do tipo: Faz bom tempo, mas estou cansado. Em enunciados assim, o locutor apresenta quatro enunciadores: E1, cujo ponto de vista é o de que faz bom tempo; E2, que justifica o convite ao passeio a partir do bom tempo; E3, que alega o cansaço e E4, que conclui, a partir do cansaço, por não fazer o passeio. Quanto às posições do locutor relativamente aos enunciadores, tem-se: a E1 dá sua aprovação; com E2 conclui favoravelmente ao passeio; o locutor se identifica com E3 e com E4. A posição do locutor é então a de recusa ao passeio.

Analisando outros enunciados que contêm o conector mas, o autor chega à construção da significação da frase da estrutura X mas $Y$, constituída por um conjunto de instruções: construa quatro enunciadores do seguinte modo: E1 contém o ponto de vista de $\mathrm{X}, \mathrm{E} 2$ tira uma conclusão a partir de X, E3 sustenta o ponto de vista de Y e E4 chega a uma conclusão 
negativa. A segunda etapa da instrução consiste em encontrar as posições do locutor em relação aos quatro enunciadores. Assim, o locutor rejeita sempre E2 e se identifica com E4 e não rejeita E1 e E3, aprovando-os ou identificando-se com eles. Portanto, a instrução diz: imagine quais são as posições do locutor e imponha alguns limites a essa imaginação. Assim, a teoria da polifonia é relacionada não só com a noção de argumentação como também com a distinção entre frase e enunciado.

A relação entre polifonia e topos exige que seja definida essa última noção. Ela surge na segunda forma da Teoria da Argumentação na Língua devido à insuficiência constatada na definição de potencial argumentativo em termos de conclusão para a descrição lingüística, definição que era assumida na forma standard da Teoria. Assim, expressões que contêm роисо e um pouco, que apontam para o mesmo fato, podem levar às mesmas conclusões, porque dependem do princípio argumentativo subjacente à argumentação. $\mathrm{O}$ trajeto argumentativo pode ser diferente em enunciados de pouco e um pouco, por exemplo, e essa noção de trajeto argumentativo é explicada por meio da noção de topos. O topos é um princípio argumentativo, um lugar-comum argumentativo, que serve de intermediário entre o argumento e a conclusão. É a garantia que assegura a passagem do argumento à conclusão. É comum, no sentido de que é compartilhado pela comunidade de fala; é geral porque vale para diversas situações de fala; é gradual porque põe em relação duas propriedades graduais, duas escalas. Derivada da noção de gradualidade surge a noção de formas tópicas: quanto mais $\mathrm{P}$, mais $\mathrm{Q}$; quanto menos $\mathrm{P}$, menos $\mathrm{Q}$; quanto mais $\mathrm{P}$ menos $\mathrm{Q}$ e quanto menos $\mathrm{P}$ mais $\mathrm{Q}$.

Ao estudar adjetivos como econômico, generoso, gastador e avarento, o autor encontra dificuldade de articulá-los por meio do conector até mesmo, que liga segmentos que utilizam o mesmo topos e a mesma forma tópica, com a particularidade de que o segundo segmento do enunciado convoca o topos de maneira mais forte do que o primeiro. Mas econômico e avarento convocam topoi contrários: econômico desvaloriza o fato de gastar, enquanto avarento o valoriza. Então, a articulação desses dois adjetivos por até mesmo parece inexplicável, no entanto a combinação desses dois adjetivos por meio de até mesmo é válida.

Para resolver esse problema, Ducrot recorre à noção de polifonia, relacionada à de topos. Assim, econômico convoca o topos quanto menos se gasta, mais valor se tem e apresenta igualmente duas vozes com dois enunciadores: E1 se identifica à pessoa de quem se fala e E2 à pessoa que fala. Em João é econômico, João desvaloriza o fato de gastar e o locutor se identifica com alguém que julga João com esse mesmo topos. Portanto, 
nesse enunciado, o locutor está dizendo duas coisas: mostra o ponto de vista de João, que é o de E1, e o seu próprio ponto de vista em relação a João, que é o de E2. Em João é avarento, há também dois enunciadores: E1, conforme ao ponto de vista de João, ponto de vista do avarento, cuja forma tópica é quanto menos se gasta mais valor se tem, e E2, ponto de vista do locutor que julga João, valorizando o gasto: quanto menos se gasta menos valor se tem. Desse modo, o adjetivo econômico é um elogio: o ponto de vista da pessoa de quem se fala é o mesmo do ponto de vista do locutor. Avarento é uma crítica, já que os pontos de vista são opostos. Com isso, consegue-se explicar por que é possível unir esses dois adjetivos por meio de até mesmo. Essa expressão é utilizada referindo-se ao ponto de vista da pessoa de quem se fala e não ao ponto de vista do locutor, quer dizer, o conector até mesmo une pontos de vista que se baseiam no mesmo topos e na mesma forma tópica. Pode-se dizer que a palavra avarento convoca a forma tópica com força superior à força a que faz alusão o adjetivo econômico.

Nessa obra de 1988, nota-se, então, um certo avanço nas reflexões sobre a polifonia. Embora a conceituação se mantenha a mesma, sua aplicação se estende às noções de argumentação e de topos e formas tópicas, que surgiram separadamente no segundo momento da Teoria da Argumentação na Língua, mas que acabaram por se unir.

\section{A NOÇAO DE ENUNCIADOR EM FOCO}

Em artigo publicado em maio de 2001, Ducrot retoma a discussão em torno da polifonia, focalizando especialmente a concepção de enunciador. Esse artigo foi escrito em resposta a críticas formuladas pela Teoria escandinava da polifonia (ScaPoLine), que propõe a exclusão da figura do enunciador. Ducrot argumenta em favor da manutenção do conceito, levantando fatos lingüísticos que só podem ser explicados por meio da distinção locutor/enunciador. Ao retornar à noção de enunciador, Ducrot acaba trazendo à luz a especificidade dessa noção em relação à de pontos de vista.

Começa lembrando três teses que estão na base da concepção de uma polifonia lingüística: (1) a tese da distinção entre sujeito falante, empírico, real, produtor efetivo do enunciado, e o locutor, ser apresentado no próprio sentido do enunciado como sendo o responsável pela sua enunciação, o que supõe que o sentido do enunciado comporta uma certa descrição de sua enunciação; (2) a tese de que certos enunciados apresentam simultaneamente vários pontos de vista ou apenas um; (3) a tese de 
que o sentido do enunciado pode atribuir ao locutor diferentes atitudes em relação ao ou aos pontos de vista, podendo haver diferentes formas e diferentes graus de adesão ou de não-adesão.

Na concepção polifônica de Ducrot, os enunciadores são definidos como seres discursivos, intermediários entre o locutor e os pontos de vista, como a fonte desses pontos de vista, como o olho que vê (2001, p. 20). O enunciador adere ao ponto de vista que lhe é atribuído e as atitudes do locutor em relação a esse ponto de vista são mediatizadas por enunciadores que podem ser seus porta-vozes. Mas o locutor pode também dar-lhes apenas sua concordância, opor-se a eles, considerá-los como objetos de desejo, de temor, etc.

O locutor põe em cena enunciadores e dá indicações sobre sua atitude em relação a eles: pode se identificar, identificar o alocutário, um terceiro ou qualquer outro ao enunciador. É na interpretação dos enunciados, logo no nível do sentido, que as instruções da significação levam a indicações completas, colocando os enunciadores do texto em relação uns com os outros, e assimilando-os eventualmente a determinado personagem suposto existir no exterior do texto, mas que são seres discursivos porque pertencem à situação que o texto apresenta como sua.

Para manter o personagem intermediário que é o enunciador, Ducrot, nesse artigo, desenvolve alguns argumentos. O primeiro argumento reside no fato de que pontos de vista diferentes podem ter a mesma fonte, mas ser objeto de atitudes diversas do locutor. Em linguagem comum, isso corresponderia ao seguinte metadiscurso: Estou de acordo contigo quando tu pensas tal coisa, mas não estou de acordo contigo quando pensas tal outra. Torna-se difícil entender como essa indicação poderia ser feita sem a noção de enunciador. Quando, num enunciado, se trata de um acordo e de uma recusa em que a identidade da fonte não pode mais derivar de uma identidade de relação do locutor com pontos de vista, mantendo-se que a menção das fontes faz parte do sentido e é prevista na significação, é cômodo, explica Ducrot, atribuir um enunciador a cada ponto de vista, enunciador que pode em seguida ser identificado com determinado personagem.

Outro caso para que seja mantida a distinção entre enunciador e ponto de vista é a da oposição entre os conectores franceses car e puisque. Estudos feitos por Ducrot mostram que não se pode introduzir por car a retomada de uma palavra dita anteriormente pelo interlocutor, enquanto essa retomada pode ser feita sem dificuldade por meio de puisque. No caso de puisque, basta mencionar o acordo entre o locutor e o ponto de vista, do que se deduz que o ponto de vista com o qual o locutor concorda 
não é o seu. Mas o locutor pode fazer mais do que dar seu acordo ao outro, ele pode retomar o ponto de vista do outro e assumi-lo como seu. Nesse caso, a figura do enunciador se torna indispensável, assumindo uma função na descrição semântica, marcando a fonte dos pontos de vista independentemente da indicação das atitudes do locutor.

Um exemplo, mencionado por Ducrot, e que conduz a manter o enunciador diz respeito à negação polêmica e à negação metalingüística, distintas da negação descritiva. Na negação descritiva, não há a noção de oposição. Mas a negação pode ter valor conflitual, opondo-se ao que é dito na sua parte positiva. Com esse valor, há duas subcategorias: a polêmica e a metalingüística. Para estabelecer essa distinção, Ducrot se baseou em testes lingüísticos. Assim, verificou que a negação às vezes mantém pressupostos do enunciado positivo e outras vezes os põe em dúvida (Os filhos de João não são grandes: ele não tem filhos). Do mesmo modo, quando a palavra negada é gradual, o efeito da negação pode ser o de assinalar um grau inferior àquele indicado pela palavra negativa (sobre o tamanho dos filhos de Pedro, alguém diz: eles não são grandes), em que há o efeito de abaixamento. Mas pode haver também a indicação de um grau superior (Eles não são grandes, mas muito grandes). Há algo em comum entre o reforço do grau e a contestação das pressuposições, mas com coisas necessárias, explica Ducrot: o valor semântico da negação deve ser colocado explicitamente depois do segmento negativo, indicando grau superior ou contestação da pressuposição; ou ainda, o enunciado negativo deve ser precedido pelo seu correspondente positivo, dito por uma terceira pessoa ou pelo interlocutor. Essas condições não são necessárias quando os pressupostos são mantidos ou abaixados.

Quando há contestação dos pressupostos ou aumento do grau, identificam-se as negações metalingüísticas, subcategoria das negações conflituais. Essa negação é sempre retificação de um enunciado positivo que a precede. Isso traz conseqüência para a teoria da polifonia. Estão na mesma categoria enunciados negativos que, conservando os pressupostos e abaixando o grau do enunciado positivo correspondente, vêm após a enunciação do alocutário ou de um terceiro (Não, eles não são grandes).

Para definir a subcategoria complementar na negação conflitual, Ducrot diz que não se trata da retificação de um enunciado positivo explícito. Esses enunciados têm um caráter conflitual que os opõe à negação descritiva. São enunciados polêmicos. Mas como definir o caráter polêmico, pergunta Ducrot, de Os filhos de Pedro não são grandes, comentário metalingüístico sobre um enunciado positivo efetivo, quando não se opõe a alguém? A resposta está ligada à polifonia, afirma ele. Nesse enunciado 
há dois pontos de vista, um em que as crianças são grandes e outro oposto. $\mathrm{O}$ locutor tem atitudes opostas: recusa o primeiro e adere ao segundo.

As posições teóricas opostas entre a proposta de Ducrot e da ScaPoLine aparece quando se representam enunciados conflituais. A noção de enunciador diz que na negação polêmica o locutor se posiciona em relação aos dois pontos de vista. A recusa do primeiro ponto de vista é um desacordo com seu enunciador. O locutor imagina alguém (o interlocutor, um terceiro) que sustentaria esse ponto de vista, e toma a posição contrária. Na negação metalingüística, o locutor do enunciado negativo se opõe, não a um enunciador, mas a outro locutor. Esse tipo de negação exige que haja uma enunciação efetiva feita por alguém de quem o locutor discorda por várias razões. Então, o locutor de um enunciado negativo metalingüístico se dá como adversário de outro locutor e não somente um enunciador identificado com seu interlocutor ou um terceiro presente. Esse enunciado, propõe Ducrot, tem, introduzido em seu sentido, um outro locutor, como acontece com certas formas de discurso relatado, principalmente discurso direto.

O terceiro argumento de que se serve Ducrot para manter a figura do enunciador em sua teoria da polifonia reúne casos intermediários entre o discurso direto, em que há outro locutor, sem lugar para os enunciadores, e os enunciados comuns que não apresentam nenhuma outra subjetividade que não seja a do locutor. Parece, então, que não há espaço para os enunciadores. Mas há os casos em que o locutor dá um realce particular aos seres que estão na origem dos pontos de vista. Um primeiro exemplo é o do estilo indireto livre. Ducrot cita uma parte de um verso de La Fontaine na fábula $O$ sapateiro e o financista: $O$ gato pegava o dinheiro... O sapateiro não disse, nem pensa que um gato roubava seu dinheiro. Há aí dois pontos de vista: alguém roubava o sapateiro (ponto de vista do sapateiro) e o barulho que levou a admitir o ponto de vista anterior é o de um gato (ponto de vista do fabulista). Isso parece indicar que há necessidade de se introduzir uma fonte do primeiro ponto de vista e essa fonte é o personagem do sapateiro. Essa observação pode ser estendida a exemplos de monólogos interiores.

Ducrot estuda um último fenômeno para mostrar que a noção de enunciador é útil. Trata-se da descrição lexical no âmbito da Teoria dos Blocos Semânticos. O desenvolvimento que será apresentado a seguir, introduzindo a teoria da polifonia na Teoria dos Blocos Semânticos, retoma de perto o texto de Ducrot, tendo em vista que a revista escandinava Polyphonie - linguistique et littéraire - é de difícil acesso entre nós.

O exemplo apresentado por Ducrot é o dos chamados verbos psicológicos do tipo procurar em estruturas do tipo: 
(a) X procura obter $Y$. Nessa estrutura é dito que $\mathrm{X}$ procura realizar um certo trabalho, conduzido pelo desejo de obter Y, crendo que isso é possível. No contexto da descrição lexical escolhida, uma primeira etapa seria condensar essa paráfrase numa frase simples:

(b) X faz um certo trabalho para obter $Y$.

A frase (b) pode ser considerada como uma conexão por meio do conector a fim de entre duas proposições subjacentes: X faz um certo trabalho e Xobtém Y. Pela Teoria dos Blocos Semânticos, descreve-se o sentido de uma unidade lingüística por um encadeamento de duas frases, encadeamento que é um espécie de paráfrase, ou seja, é a argumentação interna da entidade lexical, neste caso: procurar.

O problema está em que esse quadro teórico só reconhece, como encadeamento constitutivo do sentido, conexões do tipo de donc ou de pourtant e não conexões "psicológicas" como as de para, ou de a fim de. Ora, substituindo-se a fim de por donc obtém-se um resultado inadmissível:

(c) X faz um certo trabalho DONC obtém Y.

(c) é inadmissível porque parece implicar que $\mathrm{X}$ obtém de fato $\mathrm{Y}$, no entanto o verbo procurar não é resultativo. Mas há outro problema: de acordo com as regras para a interpretação da negação, a negação de (c) deve ser:

(d) X faz um certo trabalho POURTANT X não obtém $Y$.

A estrutura (d), que descreve $X$ procura em vão obter $Y$ não corresponde à negação de (a): X não procura obter $Y$. Essa inadequação pode ser expressa dizendo-se que (c), ao lhe ser dada a negação (d) - o que a teoria exige - , pressupõe a existência de um esforço para obter, enquanto procurar afirma essa existência, que é o seu posto.

A solução é dar pertinência a um aspecto da paráfrase inicial de (a), ou seja, à idéia de que X julga desejável e possível obter Y. Propõe-se, então, para o sentido de (a), o encadeamento (e), ao qual se pode aplicar a regra de negação:

(e) Obter Y é desejável e possivel DONC X faz um certo trabalho.

O conector DONC introduzido entre o caráter possível e desejável de $\mathrm{Y}$ e o trabalho de $\mathrm{X}$ exprime a idéia de que o trabalho é motivado por tal caráter de $\mathrm{Y}$ e que ele visa a obtenção de $\mathrm{Y}$.

Mas como fica a questão da polifonia? Ela exige que o DONC seja posto na boca ou na cabeça de X. É preciso admitir, explica Ducrot, que $\mathrm{X}$, julgando desejável obter $\mathrm{Y}$, conclui pela necessidade de realizar um certo trabalho. Para descrever (a), no quadro teórico dos Blocos Semânti- 
cos, deve-se não somente atribuir como sentido a (a) o encadeamento (e), mas ainda estipular que esse encadeamento tem X como fonte. Assim, (e) é um ponto de vista em relação ao qual o locutor de (a) pode tomar determinada atitude, mas é preciso acrescentar, para que a descrição seja adequada não somente à teoria, mas também à observação lingüística, que é $\mathrm{X}$ que está na origem do encadeamento e que $\mathrm{X}$ adere a esse ponto de vista. Isso consiste em apresentar X como o enunciador do ponto de vista (e). Introduz-se assim uma polifonia e um tipo de polifonia, atribuindo uma fonte aos pontos de vista, mostrando, ao mesmo tempo que mostra o ponto de vista, o ser discursivo de onde ele provém.

Como conclusão de seu artigo, Ducrot ainda menciona duas razões que podem manter a oposição entre locutor e enunciador, diferentemente do que propõe a ScaPoLine que exclui a noção de enunciador. A primeira razão diz respeito à natureza dos pontos de vista. Há três possibilidades: (1) são palavras apresentadas como efetivamente pronunciadas, no caso dos discursos relatados, e o responsável pelo ponto de vista é um segundo locutor, encadeado no discurso; (2) trata-se de "representações mentais", mas numa perspectiva estruturalista como a que assume a Teoria da Argumentação na Língua, não são admitidas entidades extra-lingüísticas, como é o caso desses "pensamentos" subjacentes ao discurso; (3) trata-se de palavras virtuais, que ninguém pronunciou. Essa é a proposta de Ducrot: só um locutor virtual pode ser fonte de palavras, logo um enunciador.

Segundo o autor, é preciso distinguir, nas palavras, duas funções. Uma é a de constituir uma representação da realidade, representação lingüística, aquela na qual vivemos. Essas representações concernem aos enunciadores: eles vêem as coisas, mas eles as vêem através das palavras. A segunda função é a atividade de comunicação, atividade de ação sobre os alocutários, através de discursos. Essa função é a do locutor e ele a realiza em relação a diferentes representações que constituem os "discursos" dos enunciadores.

A segunda razão para a manutenção da noção de enunciador diz respeito às relações entre polifonia textual e polifonia lingüística. A proposta de Ducrot é a de mostrar uma analogia entre a organização polifônica do texto e a dos enunciados. Para ele, o narrador de uma narrativa teria a

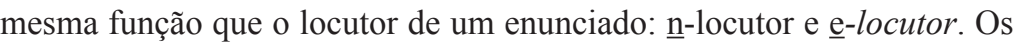
sujeitos focalizadores corresponderiam aos enunciadores dos enunciados: $\underline{n}$-enunciadores e e e-enunciadores. Do mesmo modo, o autor de uma peça de teatro, ser discursivo, seria o t-locutor e os personagens, os tenunciadores. Assim, são análogas as relações entre autor (locutor) e personagem (enunciador) do texto, e entre locutor e enunciadores do enunci- 
ado aos quais são atribuídos diversos pontos de vista, as atitudes entre locutor e enunciador podendo ser as mesmas: acordo, desacordo, identificação. Desse modo, os papéis do enunciado, relacionados à polifonia lingüística interna aos enunciados, e os que se relacionam à polifonia textual, são domínios análogos, mas distintos.

Para a ScaPoline há continuidade entre as duas polifonias. Ela busca integrar no interior do texto, tomado na sua totalidade, as diferentes vozes que se encontram nos enunciados. Sua tarefa é a de distinguir uma hierarquia de locutores que podem ser postos em relação uns com os outros. Segundo Ducrot, se de fato se chega a identificar um enunciador de um enunciado com o enunciador de outro enunciado do mesmo texto, podese dar aos enunciadores, ao mesmo tempo, um estatuto no interior do texto, tornando-se eles componentes da interpretação do texto. Mesmo sem excluir essa possibilidade, Ducrot trabalhou numa direção diferente: serviu-se dos enunciadores apenas para estabelecer o sentido de cada enunciado em que os enunciadores aparecem, e foi compondo os diferentes sentidos que ele tentou constituir uma interpretação global para o texto.

\section{PARA TERMINAR}

Pode-se afirmar, após a revisão dos textos de Oswald Ducrot aos quais se tem acesso e que tratam da questão da polifonia, aqui apresentados, que houve um trajeto percorrido pelo autor em busca da explicação desse conceito em sua Teoria da Argumentação na Língua. Partindo de trabalhos de Bally e das noções de modus e dictum, Ducrot concebe a idéia de que o pensamento expresso no enunciado não é obrigatoriamente o do sujeito falante e de que este assume determinadas atitudes relativamente ao conteúdo do enunciado. Baseado em Genette, propõe uma concepção teatral da enunciação.

Ao desenvolver, a partir dessas idéias, sua própria teoria, propõe inicialmente as figuras de locutor e de enunciador, associando este último à noção de atos ilocutórios da pragmática. Encontra assim um caminho na definição de polifonia que o afasta da menção do discurso de outro (discurso citado em estilo direto) no enunciado, que seria uma polifonia no nível do locutor e que ele não desenvolve. Prefere estabelecer distinção entre locutor e enunciador, representando o locutor sob a forma de $\mathrm{Y}$, ser no mundo, e L, responsável pelo discurso. O locutor é visto sob as formas de ser empírico, que não é objeto de estudo do lingüista, e de ser do discurso. Na polifonia dos enunciadores, estes deixam de ser sujeitos de atos ilocutórios porque não falam. São vozes, pontos de vista, com os quais o 
locutor interage.

A polifonia é ainda integrada à Teoria da Argumentação, o que é esclarecido por meio da análise de enunciados complexos. A teoria passa a ter três aspectos: o dos pontos de vista dos diferentes enunciadores; o da posição do locutor em relação aos enunciadores; o da identificação de um enunciador com uma pessoa. Nessa mesma obra (1988), é analisada a relação entre polifonia e topos.

Em seu texto publicado em 2001, Ducrot defende a tese de que o enunciador é freqüentemente intermediário entre locutor e ponto de vista, não podendo ser excluído da teoria. $\mathrm{O}$ enunciador é colocado como origem dos pontos de vista aos quais adere. Vários argumentos são utilizados para a demonstração dessa tese, entre os quais o da aplicação da polifonia à Teoria dos Blocos Semânticos, proposta que estaria merecendo um amplo desenvolvimento. Finalmente, a passagem da polifonia no enunciado para a polifonia no texto é focalizada, e uma possibilidade de metodologia para análise é sugerida.

Espera-se não se ter traído o pensamento do autor, e que este breve percurso possa ter alguma utilidade para os pesquisadores interessados no conceito de polifonia na Teoria da Argumentação na Língua.

\section{BIBLIOGRAFIA}

BAKHTIN, Mikhail. Problemas da poética de Dostoiévski. Rio de Janeiro: Forense-Universitária, 1981.

BALLY, Charles. Linguistique générale et linguistique française. Berne: Éditions Francke Berne, 1965.

BORBA, Tomás; GRAÇA, Fernando Lopes. Dicionário de música ilustrado. Lisboa: Cosmos, 1963.

DUCROT, Oswald et al. Les mots du discours. Paris: Minuit, 1980.

DUCROT, Oswald. Esboço de uma teoria polifônica da enunciação. In: . O dizer e o dito. Campinas, SP: Pontes, 1987. p. 161-218.

.Énonciation et polyphonie chez Carles Bally. In:__. Logique, structure, énonciation: lectures sur le langage. Paris: Minuit, 1989. p. 165191.

. Polifonía y argumentación: conferencias del seminario "Teoría de la Argumentación y Análisis del Discurso". Cali: Universidad del Valle, 1989.

FLORES, Valdir do Nascimento. Princípios para a definição do objeto da lingüística da enunciação: uma introdução (primeira parte). Letras de Hoje. Porto Alegre. v. 36, n. 4, p. 7-67. dez., 2001. 
NEGRONI, María Marta, TORDESILLAS, Marta. Estudios de Semántica y Pragmática. Apuntes sobre la Semántica Integrada. Revista iberoamericana de Discurso y Sociedad, Barcelona: Editorial Gedisa, v.2, n. 4, p. 3-21, dic. 2000. 